\title{
A Comparison of Readings from Thermoluminescent Dosimeter Ring Badges Worn in Different Positions
}

\author{
Keexia L. Osborne, Cybil J. Nielsen, John R. Bullock, and S. Gregory Jennings
}

Indiana University School of Medicine, Indianapolis, Indiana

\begin{abstract}
Our purpose was to evaluate whether the position of a thermoluminescent dosimeter (TLD) crystal results in different exposure readings. Methods: Nine subjects wore 2 TLD badges (one facing inward, toward the palm, and one facing outward) for 2 mo. Both TLDs were worn on the middle finger of the dominant hand, with the inward-facing TLD placed at the bottom and the outward-facing TLD at the top. At the end of the first month, these TLDs were replaced with new ones for another month. Combined results from the badges for the 2 mo were recorded in millisieverts. A paired $t$ test with 2-sample means was performed to compare the 2 positions in general nuclear medicine and PET/CT subjects, with an a of 0.05 . Results: For all subjects and for the general nuclear medicine and PET/CT groups, mean exposure was greater for the inward-facing TLD. Conclusion: For a TLD worn on the dominant hand, extremityexposure readings are maximized when the TLD faces inward.
\end{abstract}

Key Words: crystal; position; thermoluminescent dosimeter; exposure rates; radiation

J Nucl Med Technol 2020; 48:361-362

DOI: 10.2967/jnmt.120.243345

\section{$\mathbf{R}$}

adiation workers wear thermoluminescent dosimeters (TLDs) to monitor exposure of their extremities to radiation. TLDs should be worn on the dominant hand facing inward (toward the palm) because this position provides a more accurate reading $(1,2)$.

Regular monitoring is important to prevent surpassing the annual limit on exposure. For the extremities, this limit is $500 \mathrm{mSv}(1)$.

A previous study was conducted using 2 technologists for 16 mo (3). The technologists wore 2 TLDs on their dominant hand, with one placed inward and the other placed outward. The purpose of that study was to determine whether there was a difference in exposure to the anterior and posterior sides of the finger. The results indicated that the reading for the TLD facing outward was equal to or greater than that for the TLD facing inward. That study had several limitations. First, only 2 radiation workers were used. Second, only exposure from general nuclear medicine was used. Third, it was not stated how the TLDs were worn by the technologist.

Received Feb. 7, 2020; revision accepted Apr. 24, 2020.

For correspondence or reprints contact: Keexia L. Osborne, Indiana University

School of Medicine, 1120 W. Michigan St., CL-118, Indianapolis, IN 46202.

E-mail: keeosbor@iu.edu

Published online Jun. 9, 2020.

COPYRIGHT (c) 2020 by the Society of Nuclear Medicine and Molecular Imaging.
Radiation workers may not be consistent in how they wear their TLDs. TLDs can be worn with the crystal facing inward or outward. The best way to wear a TLD is whichever way will maximize the exposure. Working in PET may yield a higher radiation exposure than working in general nuclear medicine because PET deals with a higher energy, $511 \mathrm{keV}$, than the $140 \mathrm{keV}$ used in general nuclear medicine (4). In PET, the highest contributor to exposure of the extremities comes from administering the dose (5), whereas the greatest exposure in general nuclear medicine comes from preparing the dose (2). The purpose of this research was to evaluate whether the position of a TLD crystal results in different exposure readings in subjects who work in general nuclear medicine and in a separate group of subjects who work in PET/CT.

\section{MATERIALS AND METHODS}

Institutional review board approval was obtained before this prospective study began. Nine radiology workers were solicited to participate as subjects. They were divided into 2 groups: general nuclear medicine (6 subjects) and PET/CT (3 subjects). Eight subjects were righthand dominant, and 1 subject was left-hand dominant. There were 18 data points. A paired 2-sample $t$ test was used with an $\alpha$ of 0.05 to indicate statistical significance. The results were recorded in millisieverts.

The study materials included 36 lithium fluoride ring badges (Landauer) and dosimetry reports. Each subject wore 2 TLDs, one with the crystal facing inward and one with the crystal facing outward. Both were worn on the middle finger of the dominant hand. The inward-facing TLD was placed at the bottom and the outward-facing TLD at the top (Fig. 1). After 1 mo, the TLDs were replaced with new ones, which were worn for another month. At the conclusion of each month, the TLDs were sent to Landauer for reading.

\section{RESULTS}

For the subjects as a whole, the mean readings were 1.84 $\mathrm{mSv}$ for the inward-facing TLD and $1.26 \mathrm{mSv}$ for the outward-facing TLD $(P=0.0013)$ (Table 1$)$. The respective readings were 1.27 and $0.93 \mathrm{mS}$ for the general nuclear medicine subjects and 2.97 and $1.92 \mathrm{mSv}$ for the PET/CT subjects. Exposure of the TLD facing inward was almost always higher for the general nuclear medicine subjects and was always higher for the PET/CT subjects (Table 2).

\section{DISCUSSION}

We found a statistically significant difference in exposure readings when comparing inward- and outward-facing TLDs, for both general nuclear medicine subjects and 
FIGURE 1. Position of TLDs.

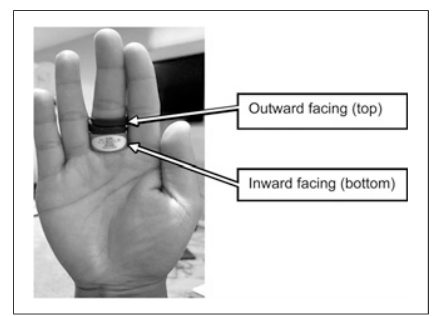

PET/CT subjects. These findings are important because radiation workers should wear TLDs in whichever way will maximize exposure. When the TLD is worn on the dominant hand, the inwardfacing position yields the highest reading.

Unlike our study, a previous study concluded that facing a TLD outward gave a higher exposure reading (3). Reasons for this difference could be that our study included more subjects and that some of these subjects worked with PET/CT rather than only general nuclear medicine.

One limitation of our study was a difficulty in keeping the TLDs positioned consistently throughout the day. The position can change when gloves are put on or if the worker has a habit of spinning the ring or switching it to another finger. In addition, having the outward-facing ring on the top and the inward-facing ring on the bottom might slightly affect the results because of a slight difference in location on the finger itself. Other limitations were the limited study duration $(2 \mathrm{mo})$ and sample size (18 data points).

Further research is needed on more subjects over a longer period, with methods put in place to control rotation and placement (top vs. bottom) of the rings. As in the current study, future studies should include both general nuclear medicine subjects and PET/CT subjects because of the higher exposure of the extremities in the latter.

TABLE 1

Comparison of Readings from Inward- and Outward-Facing TLDs

\begin{tabular}{lccccc}
\hline Group & $\begin{array}{c}\text { Inward } \\
\text { Mean }\end{array}$ & Variance & $\begin{array}{c}\text { Outward } \\
\text { Mean }\end{array}$ & $P^{*}$ \\
& Variance & \\
\hline All subjects & 1.84 & 2.59 & 1.26 & 1.09 & 0.00 \\
$\begin{array}{l}\text { General nuclear } \\
\text { medicine }\end{array}$ & 1.27 & 1.17 & 0.93 & 0.75 & 0.00 \\
PET/CT & 2.97 & 3.93 & 1.92 & 1.27 & 0.03 \\
& & & & & \\
& & & & & \\
* $(T<t)$ 2-tailed. \\
Data are in millisieverts.
\end{tabular}

TABLE 2

Individual Readings from Inward-and Outward-Facing TLDs

\begin{tabular}{ccc}
\hline Subject no. & Inward & Outward \\
\hline General nuclear medicine & & \\
1 & 2.13 & 2.19 \\
2 & 1.22 & 0.89 \\
3 & 0.42 & 0.23 \\
4 & 0.25 & 0.13 \\
5 & 1.94 & 1.50 \\
6 & 3.61 & 2.53 \\
7 & 0.67 & 0.34 \\
8 & 2.38 & 1.74 \\
9 & 0.92 & 0.42 \\
10 & 1.53 & 1.05 \\
11 & 0.24 & 0.20 \\
$12^{*}$ & 0.00 & 0.00 \\
PET/CT & & \\
13 & 2.65 & 2.00 \\
14 & 3.99 & 2.41 \\
15 & 6.48 & 3.90 \\
16 & 1.50 & 1.02 \\
$17^{\star}$ & 1.17 & 0.91 \\
18 & 2.07 & 1.29 \\
\hline
\end{tabular}

*Left-hand dominant.

Data are in millisieverts.

There were 9 subjects; each subject was 2 data points, as each subject had 2 results, month one and month two.

\section{CONCLUSION}

Readings for a TLD worn on the dominant hand are maximized when the TLD faces inward.

\section{DISCLOSURE}

No potential conflict of interest relevant to this article was reported.

\section{REFERENCES}

1. Nielsen CJ. Radiation safety certification: a review. J Nucl Med Technol. 2018; 46:321-325.

2. Burr JE, Berg R. Radiation dose to hands from radiopharmaceuticals: preparation versus injections [abstract]. J Nucl Med Technol. 1977;5:158-160.

3. Adcock D, Harp E, Zurosky DM. Ring badge position for nuclear medicine technologists [abstract]. J Nucl Med Technol. 1995;23:33-35.

4. Roberts FO, Gunawardana DH, Pathmaraj K, et al. Radiation dose to PET technologists and strategies to lower occupational exposure. J Nucl Med Technol. 2005;33:44-47.

5. Costa PF, Testanera G, Camoni L, et al. Technologist approach to global dose optimization. J Nucl Med Technol. 2019;47:75-82. 